East African Medical Journal Vol. 87 No. 3 March 2010

RESISTANCE TO ANTIBIOTICS IN URINOPATHOGENIC BACTERIA ISOLATED IN PATIENTS ATTENDING KENYATTA UNIVERSITY HEALTH CLINIC, NAIROBI

J. M. Kimando, HDMLT, MSc, Senior Laboratory Technologist, Kenyatta University Health Unit, Department of Biochemistry and Biotechnology, P. O. Okemo, BSc, MSc, PhD, Associate Professor, Department of Plant and Microbial Sciences and E. N. M. Njagi, BSc, MSc, PhD, Associate Professor, Department of Biochemistry and Biotechnology, Kenyatta University, P.O. Box 43844 - 0010, Nairobi, Kenya

Request for reprints to: Mr. J. M. Kimando, Department of Biochemistry and Biotechnology, Kenyatta University, P.O. Box 43844 - 0010, Nairobi, Kenya

\title{
RESISTANCE TO ANTIBIOTICS IN URINOPATHOGENIC BACTERIA ISOLATED IN PATIENTS ATTENDING KENYATTA UNIVERSITY HEALTH CLINIC, NAIROBI
}

\author{
J. M. KIMANDO, P. O. OKEMO and E. N. M. NJAGI
}

\begin{abstract}
Objective: To determine the aetiological bacterial agents of urinary tract infections, within communities in Kenyatta University, and current resistance levels to commonly available therapeutic agents.

Design: Cross-sectional survey research design.

Setting: Kenyatta University Health Services Clinic, Nairobi.

Subjects: Outpatients with symptoms of urinary tract infection within the six months study duration were observed.

Results: Females were particularly prone to have confirmed cases of UTI. Escherichia coli were the principle aetiological agent accounting for $61.7 \%$ of the isolates. Other bacterial agents were Enterobacter agglomerans (18.7\%), Citrobacter diversus (4\%), Klebsiella pneumoniae (3.3\%), Proteus spp. (2.1\%), Pseudomonas spp. (0.1\%), Staphylococcus saprophyticus $(9.3 \%)$, and Streptococcus feacalis $(0.7 \%)$. Over $60 \%$ of the Gram negative bacterial isolates were resistant to cotrimoxazole and ampicillin, $39 \%$ resistant to augmentin and $25 \%$ were resistant to nalidixic acid. The ceftazidime was the most efficacious antimicrobial with an Escherichia coli resistance level of $2.2 \%(P=0.05)$. Resistance to nitrofuraintoin, gentamicin, cefuroxime, norfloxacin and ciprofloxacin was demonstrated in less than $15 \%$ of the bacterial isolates.

Conclusion: The cephalosporins, fluoroquinolones, nitrofurantoin and gentamicin have good efficacy against the uropathogenic bacteria and may be good therapeutic choices when culture results are unavailable. High resistance levels exist against cotrimoxazole, ampicillin, augmentin, and nalidixic acid. These later antibiotics should therefore be used against the uropathogenic bacteria with caution.
\end{abstract}

\section{INTRODUCTION}

The antimicrobial resistance in epidemic diseases like tuberculosis, typhoid or dysentery is relatively well characterised through nationwide surveillance systems that monitor these diseases and their aetiology, but not so for sporadic diseases such as cystitis (UTI) that can be caused by resistant bacteria, because they are not similarly monitored. Urinary tract infections are third ranked in the list of most common bacterial infections, and are the mostfrequent bacterial infections in women (1). Recurrent infections become a problem in $25 \%-30 \%$ of women who experience an initial infection (2). Studies on antimicrobial susceptibility patterns show wide variations among communities, hospitals, and geographicregions (3).Studies reporting on antimicrobial resistance in uropathogenic bacteria in Kenya have originated from the Kenyatta National Referral and Teaching Hospital (4), and their findings may not truly capture the current antimicrobial resistance trends in other communities. This study was designed to identify prevailing uropathogens in the Kenyatta University community and their susceptibility to commonly available therapeutic agents.

\section{MATERIALS AND METHODS}

The study adopted a cross-sectional survey research design, and the study population consisted of out patients with symptoms of UTls who sought treatment at the Kenyatta University Health Services Clinic. The 
study was approved by the MedicalOfficerincharge of the Kenyatta University Health Services and granted ethical clearance by the KEMRI/ National Ethical Review Committee. Informed patient's consent was sought and obtained from the participants.

The clinic serves a community of approximately 21,000 undergraduate students, 2,500 postgraduate students, and 2,436 employees and their dependants, representing a population that comes from across the country.

A total of 450 fresh midstream urine samples were collected in sterile universal bottles using previously described methods (5). The samples were examined macroscopically for physical characteristics such as turbidity, clarity, colour, and a biochemical analysis performed with the multistix (Bayer, USA), to test for $\mathrm{pH}$, leukocytes, nitrite, protein, glucose, specific gravity, bilirubin, urobilinogen, ketones, and presence of blood. The urine samples were cultured on cystine-lactose electrolyte-deficient (CLED) agar (oxoid, UK) following the semi quantitative culture method (6). Bacterial growths of $\geq 10^{5}$ colony forming units / $\mathrm{ml}$ of urine were identified using standard microbiological procedures.

The agar disk diffusion method was used to conduct the sensitivity testing (7). The bacterial inoculum was suspended in sterile saline $(0.85 \%$ $\mathrm{NaCI}$ ) and the turbidity adjusted to $0.5 \mathrm{McFarland}$ standard. The bacterial suspension was streaked onto Mueller-Hintoin agar (Oxoid, UK), and tested against the following antibiotics concentrations, augmentin $30 \mu \mathrm{g}$, cefuroxime $30 \mu \mathrm{g}$, nitrofurantoin $200 \mu \mathrm{g}$, nalidixic acid $30 \mu \mathrm{g}$, gentamicin $10 \mu \mathrm{g}$, norfloxacin $5 \mu \mathrm{g}$, cotimoxazole $75 \mu \mathrm{g}$, ampicillin $25 \mu \mathrm{g}$, ciprofloxacin $5 \mu \mathrm{g}$, and ceftazidime $30 \mu \mathrm{g}$. The $100 \mathrm{NH} 6$ and 100KGL disks (Biotec Ltd, England) and for some antibiotics, individual disks (Oxoid, UK) were used to perform the susceptibility testing.

Forthequality controlofantimicrobial susceptibility testing, Escherichia coli strain ATCC 25922 was included in the tests alongside the isolates.

Statistical analysis: Frequencies and percentages were used to present and summarise data. The chisquare and Fisher's exact test were used to compare categorical variables. A two tailed p-value of less than 0.05 was considered to be statistically significant.

\section{RESULTS}

Characteristics of the urine samples: Out of the 450 fresh urine samples, 150 grew bacteria of clinical significance, making an isolation rate of $33.33 \%$ (Table 1). Thirty one per cent females and $2 \%$ males had confirmed UTls (significant bacterial growth). There was a statistically significant association between confirmed UTIs and gender $\left(\chi^{2}=64.8\right.$, $\mathrm{df}=1, \mathrm{P}<0.05)$, with females more likely to have confirmed UTIs. Twenty eight per cent of the sampled patients had confirmed bacterial UTIs and turbid urine samples. There was a statistically significant association between culture confirmed UTIs and turbidity $\left(\chi^{2}=338, \mathrm{df}=1, \mathrm{P}<0.05\right)$.

Characteristic of culture positive patients: Thirty eight of the $150(25 \%)$ culture positive patients had recorded usage of antibiotics in the last three months prior to urine collection, with females constituting $36 / 150(24 \%)$ and males $2 / 150$ $(1.3 \%)$ of the patients with such history. However, there was no statistically significant association between gender and previous usage of antibiotics $\left.\chi^{2}=0.161, \mathrm{df}=1, \mathrm{P}>0.05\right)$. Among the culture positive patients, the most commonly prescribed antimicrobial agents in the last three months prior to this survey (Table 2), were penicillins (amoxicillin, ampicillin and augmentin) at 47.5\%, followed by fluoroquinolones (ciprofloxacin and norfloxacin) at $20.1 \%$, and cotrimoxazole $(7.5 \%)$. Ampicillin and cotrimoxazole had lower usage rates than the fluoroquinolones. The gentamicin and nitrofurantoin had minimal utilisation rates in the community at $0.7 \%$ each.

Aetiological agents: Eight genera of bacterial aetiological agents of UTI were isolated (Table 3). Ninety per cent were gram-negative bacilli such as Escherichia, Enterobacter, Citrobacter, Klebsiella, Proteus and Pseudomonas. The remaining $10 \%$ of the bacterial aetiological agents were Gram-positive cocci which included Staphylococcus and Streptococcus.

Table 1

Patients gender, turbidity of urine samples and culture results

\begin{tabular}{|c|c|c|c|c|c|c|c|c|c|}
\hline \multirow[t]{3}{*}{ Gender } & \multirow{2}{*}{\multicolumn{2}{|c|}{$\begin{array}{l}\text { Turbid samples } \\
\text { Growth }\end{array}$}} & \multicolumn{3}{|c|}{ Clear samples } & \multicolumn{2}{|c|}{ Total $(\%)$} & & \multirow[b]{3}{*}{ No. $(\%)$} \\
\hline & & & \multirow{2}{*}{\multicolumn{2}{|c|}{ No growth }} & \multicolumn{2}{|c|}{ Growth } & No growth & & \\
\hline & No. & $(\%)$ & & & No. & $(\%)$ & No. & $(\%)$ & \\
\hline Female & 121 & 26.9 & 4 & 0.9 & 21 & 4.7 & 167 & 37.1 & 31369.6 \\
\hline Male & 7 & 1.5 & 1 & 0.2 & 1 & 0.2 & 128 & 28.5 & 13730.4 \\
\hline Total & 128 & 28.4 & 5 & 1.1 & 22 & 4.9 & 295 & 65.5 & 450100 \\
\hline
\end{tabular}


Table 2

Usage of antimicrobial agents among culture positive patients in the last three months

\begin{tabular}{|c|c|c|c|}
\hline Antimicrobial agent & Frequency & $\begin{array}{l}\text { Antimicrobial } \\
(\%) \text { use }\end{array}$ & $\begin{array}{l}\text { Antimicrobial } \\
\text { Class }(\%) \text { use }\end{array}$ \\
\hline Penicillins & & & 47.5 \\
\hline Augmentin & 16 & 40 & \\
\hline Ampicillin & 3 & 7.5 & \\
\hline Cephalosporin & & & 2.5 \\
\hline Cefuroxime & 1 & 2.5 & \\
\hline Fluoroquinolone & & & 20 \\
\hline Ciprofloxacin & 5 & 12.5 & \\
\hline Norfloxacin & 3 & 7.5 & \\
\hline Aminoglycoside & & & 10 \\
\hline Gentamicin & 1 & 2.5 & \\
\hline Minocycline & 3 & 7.5 & \\
\hline Sulphonamide & & & 7.5 \\
\hline Cotrimoxazole & 3 & 7.5 & \\
\hline Nitrofurantoin & 1 & 2.5 & 2.5 \\
\hline Other & 1 & 2.5 & 2.5 \\
\hline Combined antimicrobial therapy & 3 & 7.5 & 7.5 \\
\hline Total & 40 & 100 & 100 \\
\hline
\end{tabular}

Table 3

Aetiological bacterial isolates

\begin{tabular}{lll}
\hline Bacteria & No. & $(\%)$ \\
\hline Gram-negative bacilli & & \\
Escherichia coli & 92 & 61.3 \\
Enterobacter agglomerans & 28 & 18.7 \\
Citrobacter diversus & 6 & 4.0 \\
Klebsiella pneumoniae & 5 & 3.3 \\
Proteus vulgaris & 1 & 0.7 \\
Proteus mirabilis & 1 & 0.7 \\
Proteus morganii & 1 & 0.7 \\
Pseudomonas & 1 & 0.1 \\
Gram-positive cocci & & \\
Staphylococcus saprophyticus & 14 & 9.3 \\
Streptococcus feacalis & 1 & 0.7 \\
\hline Total & 150 & 100 \\
\hline
\end{tabular}

Susceptibility pattern of the isolates: The isolates exhibited varying trends of susceptibility and resistance to the therapeutic agents (Table 4). Antibiotics that demonstrated good efficacy were; ceftazidime which was effective on over $90 \%$ of gram negative bacterial isolates, while gentamicin, ciprofloxacin, norfloxacin, and nitrofurantoin were effective to over $80 \%$ of the isolates. The isolates were moderately sensitive to cefuroxime (over $70 \%$ ), but exhibited low susceptibility (less than 55\%) to nalidixic acid and augmentin among the E. coli strains and some other Gram negativebacteria. Ampicillin and cotrimoxazole exhibited very poor efficacy among the Gram negative bacterial isolates (effective on less than $36 \%$ ), although ampicillin demonstrated better efficacy $(78 \%)$ on the Staphylococcus saprophyticus strains.

Table 4

Susceptibility patterns for all the isolates

\begin{tabular}{|c|c|c|c|c|c|c|c|c|c|c|c|c|}
\hline \multirow[t]{2}{*}{ Antibiotic } & \multicolumn{2}{|c|}{$\begin{array}{l}\text { E. coli } \\
\quad(\mathrm{n}=92)\end{array}$} & \multicolumn{4}{|c|}{$\begin{array}{c}\text { Enterococcus spp. } \\
(\mathrm{n}=28)\end{array}$} & \multicolumn{3}{|c|}{$\begin{array}{l}\text { Citrobacter spp. } \\
\text { Klebsiella spp. } \\
(\mathrm{n}=11)\end{array}$} & \multicolumn{3}{|c|}{$\begin{array}{l}\text { Staphylococcus } \\
\text { spp. } \\
\quad(\mathrm{n}=14)\end{array}$} \\
\hline & $\mathrm{S} \%$ & $1 \%$ & $\mathrm{R} \%$ & $\mathrm{~S} \%$ & $1 \%$ & $\mathrm{R} \%$ & $\mathrm{~S} \%$ & $1 \%$ & $\mathrm{R} \%$ & $\mathrm{~S} \%$ & $1 \%$ & $\mathrm{R} \%$ \\
\hline Augmentin & 30.43 & 10.87 & 58.69 & 50 & 10.7 & 39.3 & 36.4 & 0 & 63.6 & 85.8 & 7.1 & 7.1 \\
\hline Cefuroxime & 70.65 & 17.39 & 11.96 & 85.7 & 10.7 & 3.6 & 72.7 & 0 & 27.3 & 92.9 & 7.1 & 0 \\
\hline Ciprofloxacin & 92.39 & 1.09 & 6.52 & 85.7 & 3.6 & 10.7 & 90.9 & 0 & 9.1 & 81.4 & 18.6 & 0 \\
\hline Nitrofurantoin & 85.87 & 8.70 & 5.43 & 82.1 & 7.2 & 10.7 & 63.6 & 18.2 & 18.2 & 85.7 & 0 & 14.3 \\
\hline Nalidixic acid & 55.44 & 13.04 & 31.52 & 71.4 & 3.6 & 25 & 45.4 & 36.4 & 18.2 & 28.6 & 0 & 71.4 \\
\hline Gentamicin & 90.21 & 1.09 & 8.69 & 92.9 & 0 & 7.1 & 81.8 & 0 & 18.2 & 78.6 & 0 & 21.4 \\
\hline Ceftazdime & 97.8 & 0 & 2.2 & 96.4 & 0 & 3.6 & 90.9 & 0 & 9.1 & 92.9 & 7.1 & 0 \\
\hline Cotrimoxazole & 10.8 & 72.17 & 86.95 & 17.9 & 0 & 82.1 & 27.3 & 9.1 & 63.6 & 57.1 & 0 & 42.9 \\
\hline Ampicillin & 16.30 & 1.09 & 82.61 & 35.7 & 0 & 64.3 & 9.1 & 9.1 & 81.8 & 78.6 & 7.1 & 14.3 \\
\hline Norfloxacin & 86.95 & 1.09 & 11.96 & 82.1 & 3.6 & 14.3 & 81.8 & 9.1 & 9.1 & 78.6 & 21.40 & \\
\hline
\end{tabular}

$\mathrm{S}=$ Sensitive, $\mathrm{I}=$ intermediate susceptibility, $\mathrm{R}=$ Resistant 


\section{DISCUSSION}

The isolation rate $(33.33 \%)$ obtained in this study suggests that symptoms of UTI alone are not an adequate guide on which to base diagnosis and subsequent antimicrobial therapy decisions in urinary tract infections. This compares closely with an isolation rate of $39.5 \%$ obtained by a previous study in a teaching and referral hospital in Ethiopia (8). The large proportion of patients who presented with symptoms of UTI but did not yield positive bacterial cultures $(66.7 \%)$ accentuate the need for laboratory diagnosis in UTls to avoid misdiagnosis and subsequent unnecessary treatment.

Turbidity in urine was however a good indicator for a culture positive UTI in this study $\left(\chi^{2}=338, \mathrm{df}\right.$ $=1, \mathrm{P}<0.05)$. A previous study in outpatients with UTIs reported a $66 \%$ positive predictive value for finding a culture positive UTI from turbid samples (9). Therefore, turbidity in urine presents a tool that can be used by patients in presumptive self diagnosis of UTI. Among the confirmed UTI cases, females were more prone than males. Previous studies (10) have shown females athigher risk of UTIs. There is therefore need to sensitise females on clinical symptoms to aid in self diagnosis, importance in seeking immediate treatment, and knowledge of control measures.

Twenty five per cent of patients with confirmed UTIs had recorded usage of antibiotic in the last three months, but the association was not stastically significant $\left(\chi^{2}=0.161, \mathrm{df}=1, P>0.05\right)$. The study found that the flouroquinolones have a higher previous usage rate than the cotrimoxazole and ampicillin, which for long have been the recommended first line of treatment. This contrast with studies from the developed world (2) that show the later two drugs have high usage in UTI therapy. Cotrimoxazole and ampicillin are available over the counter in Kenya (14) and most bacteria have developed resistance. In addition, importation of counterfeit drugs which contain lower levels of active ingradients could be another contributory factor. The higher usage of fluoroquinolones recorded in this study may lead to an increase in resistance if stringent prescription measures are not observed.

Escherichia coli were the principle aetiological agent, followed by Enterobacter agglomerans, Citrobacter diversus, Klebsiella pneumoniae, and Proteus spp. The uropathogenic bacteria in this aetiological profile have been reported in the USA (11), in Dakar, Senegal (12), and in Tanzania (13). However, a notable variation in the aetiological profile from other studies carried out in referral hospitals $(8,13)$ is the prevalence of Enterobacter agglomerans as the second most frequent aetiological agent demonstrated in this study. This is a clear indication that variation in community acquired UTI, and antimicrobial susceptibility should be monitored constantly in order to capture any emerging resistance due to frequent gene transfers.
High resistance rates among the isolates to cotrimoxazole and ampicillin were observed, confirming earlier reported rates for these drugs at over 70\% in community acquired bacterial infections in Kenya (4), and in Nigeria, Ethiopia, and Senegal $(8,12,14)$. The high resistance prevalence rates are a reflection of the widespread use of these two antibiotics over many years, combined with failure to respect ethics in antibiotic use in Africa (15). There is need to review the first-line therapy antimicrobials and consider alternative therapies. In contrast, the national resistance prevalence rates to ampicillin and cotrimoxazole in the USA has been reported at $38 \%$ and less than $24 \%$ respectively (16), probably due to surveillance and observation of ethics in drug prescription and rational use. In the USA the cotrimoxazole is used as empiric therapy for uncomplicated UTI in some regions where resistance is $20 \%$ and less (16).

The E. coli bacterial isolates exhibited a resistance rate of $12 \%$ to cefuroxime, a finding that is significantly higher than that of below 5\% reported in previous studies in the 1990s $(16,21)$. It is evident that with use over the years, resistance to this drug is on the rise. This could be the outcome of widespread selfmedication and abuse of ethics by pharmacists in over the counter sales. Only $2.2 \%$ of the bacterial isolates demonstrated resistance to ceftazidime. Ceftazidime is an expensive antibiotic, which restricts its use and abuse (15). Both cefuroxime and ceftazidime may be considered as alternative therapy for resistant UTIs in the community.

The newer fluoroquinolones, namely ciprofloxacin and norfloxacin that form the main line of therapy for UTIs, show a good but decreasing in vitro efficacy for the isolates, with resistance prevalence rates of about $10 \%$, a finding reported in other countries (8). In some African countries, higher resistance rates of over $20 \%$ have been reported (14). However, markedly higher susceptibility has been reported in Europe and USA, where resistance rates are $2.6 \%$ and below (16). The lower resistance levels in Europe can be traced to prudent antibiotic use (17). The Gram negative bacterial isolates exhibited the highest resistance (31.5\%) to nalidixic acid, an older quinolone. This finding is markedly different from that of less than $10 \%$ reported in previous studies (4). The increasing resistance to flouroquinolones may be due to an increase in prescribing practice, which calls for continuous monitoring of resistance and restricting their use in therapy of uncomplicated UTIs in order to preserve their effectiveness.

Gentamicin, an aminoglycoside, showed high efficacy for all the isolates. This has been reported in previous studies in Africa $(4,8)$, and in the USA (1). This antibiotic has been in use for over 50 years and still retains potency. However, there is limited usage of this drug in the study community probably because its administration as an injection drug may 
not be desirable to many patients. The limited usage has delayed the emergence and spread of resistance to the drug.

Nitrofurantoin showed good susceptibility (over $82 \%$ ) for most bacterial isolates, although resistance rate of less than $10 \%$ had been reported in previous studies in Kenya (4). Nitrofurantoin is one of the oldest urinary antibacterial agents still in use. This antibiotic is thought to have many modes of action that delay emergence of resistance and co-resistance. This study observed that nitrofuraintoin is rarely prescribed in the community studied, which may also explain the low resistance prevalence rates despite availability in the market for a longer duration.

\section{ACKNOWLEDGEMENTS}

The authors wish to appreciate help given by Kenyatta University, especially the Head, Kenyatta University Health Unit, Dr. A. C. Osundwa, for granting approval to conduct this study at the clinic. We acknowledge the valuable participation and cooperation of the clinicians at the clinic that ensured sampling ran smoothly. We further acknowledge the technical support of laboratory staff at the Kenyatta University Health Unit, particularly Mr. K. Mwaura, Ms. L. Warungu and Mr. Z. Nandwa.

\section{REFERENCES}

1. Stamm, W.E. An epidemic of urinary tract infections. New Eng. J. Med. 2001; 345: 1055-1057.

2. Car, J., Vab, L. S., Kersnika, J. and Miljana V. Management of lower urinary tract infection in women by Slovene GPs. Family Practice. 2003; 20: 452-456.

3. Gupta, K., Hooton, T.M. and Stam, W.E. Increasing antimicrobial resistance and the management of uncomplicated community - acquired urinary tract infections. Annals Intern. Med. 2001; 135: 41- 50.

4. Malonza, I.M., Omari, M.A., Bway, A. K. et al. Community acquired bacterial infections and their antimicrobial susceptibility in Nairobi. East Afr. Med. J. 1997; 74: 166 - 170.

5. Fisher, A.A., Laing, J.E. Stoeckel, J.E. and Townsend, J. J. In:Handbook for family planning operations research design, 2nd edition, Population Council, New York, USA 1998.
6. Baron, E. J. O., Peterson, L.R. and Finegold, S. M. Enterobacteriaceae. In: Diagnostic Microbiology, 9th edition, Bailey and Scott's, Mosby, USA. 1998; pp362-385.

7. Bauer, A.W., Kirby, M.W. Sherris, J.C. and Turk, M. Antibiotic susceptibility testing by standardized single disc method. Amer. J. Clin. Path. 1966; 45: 495 - 496.

8. Moges, A.F., Genetu, A. and Mengistu, G. Antibiotic sensitivities of common bacterial pathogens in urinary tract infections at Gondar Hospital. East Afr. Med. J. 2002; 79: 140 -142.

9. Richards, D., Toop, L., Chambers, S. and Fletcher, L. Response to antibiotics of women with symptoms of urinary tract infection but negative dipstick urine test results: double blind randomised controlled trial. Brit. Med. J. 2005; 10: 1136-1141.

10. Stamm, W.E. and Norrby S. R. Urinary tract infections: disease panorama and challenges. J. Infect. Dis. 2001; 183: $51-54$.

11. Joshua, P.M., Strom, B. L. and Asch, D. A. Prior antimicrobial drug exposure: a risk factor for trimethoprom-sulfamethoxazole resistant urinary tract infections. J. Antimicrobial Agents Chemo. 2003; 51: 963-970.

12. Dromigny, J.A., Ndoye, B. Macondo, E. A., et al. Increasing prevalence of antimicrobial resistance among the Enterobacteriaceae. Diag. Microb. Infect. Dis. 2003; 47: $595-600$.

13. Urassa, W.K., Mwakagile, D. Mohammed, K. and Msangi, V. Susceptibility pattern of uropathogenic gram negative bacilli to antimicrobial chemotherapeutic agents in a national hospital in Dar es Salaam. East Afr. Med. J. 1997; 74: 162 - 165.

14. Daini, O.A., Ogbilu, O.D. and Ogunledun, A. Quinolones resistance and $\mathrm{R}$ plasmids of some gram negative enteric bacilli. Afr. J. Clin. Exper. Micro. 2005; 6: $14-20$.

15. Indalo, A.A. Antibiotic sale behavior in Nairobi: Acontributing factor to antimicrobial drug resistance. East Afr. Med. J. 1997; 74: 171 -173.

16. Karlowsky, J.A., Lwlly, C.J. Thornsberry, C., Jones, M.E. and Sahrn D.F. Trends in antimicrobial resistance among urinary tract isolates of Escherichia coli from female outpatients in the United States. Antimicrobial Agents and Chemotherapy. 2002; 46: 2540-2545.

17. Zhanel, G.G., Karlowsky, J. A., Harding, G.K. et al. A Canadian national surveillance study of urinary tract isolates from outpatients. Comparison of the activities of trimethoprim - sulfamethoxazole and ciprofloxacin. J. Antimicrobial Chemotherapy. 2000; 44: 1089-1092. 